
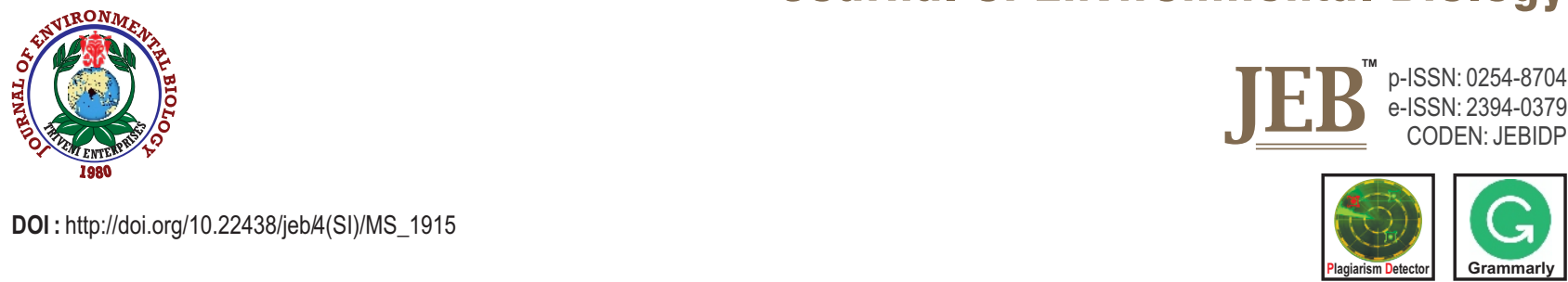

\title{
Effects of low-dose irradiation on chromosomal damage and oxidative stress in cultured human peripheral blood
}

\author{
M. Zosangzuali', L. Pachuau' ${ }^{2}$, K.S. Pau ${ }^{3}$ and Zothansiama* \\ 'Department of Zoology, Mizoram University, Aizawl - 796 004, India \\ ${ }^{2}$ Department of Physics, Pachhunga University College, Aizawl-796 001, India \\ ${ }^{3}$ Radiation Safety Agency, Directorate of Hospital and Medical Education, Aizawl-796 001, India \\ *Corresponding Author Email : zothans@gmail.com
}

\section{Abstract}

Aim: To investigate the effects of low doses of $X$-ray exposure on chromosomal damage and antioxidants level in cultured human peripheral blood.

Methodology: Blood samples collected from healthy young volunteers (male and female) in sterile heparinized tubes were irradiated at $97 \mathrm{kVp}$ with 300 $\mathrm{mAs}$ using X-rays machine. In-vitro irradiation of whole blood was performed at different doses $(0,25,50,100,200$ and $300 \mathrm{mGy})$ with an average dose rate of $19.6 \mathrm{mGysec}^{-1}$. After irradiation, the lymphocytes were collected and cultured for $72 \mathrm{hr}$. Micronuclei (MN) assay was carried out following the standard protocol for the assessment of chromosomal damage. The level of glutathione (GSH), activities of glutathione-s-transferase (GST) and superoxide dismutase (SOD) were estimated from the blood plasma. Malondialdehyde (MDA) content was also estimated to determine oxidative stress after low-dose irradiation.

Results: A significant positive correlation $\left(r^{2}=0.98, p<0.001\right)$ was observed between total MN frequency and irradiation dose in human peripheral blood lymphocytes. Irradiation of blood also caused significant decrease in GSH level and GST activities with increased in irradiation dose. Significant reduction in SOD activity was observed only at doses $\geq 100 \mathrm{mGy}$. Induction of oxidative stress in human blood due to irradiation was clearly evident from enhanced MDA content.

Interpretation: This study indicates that exposure to ionizing radiation less than 100 mGy can cause genetic damage and induce oxidative stress. Furthermore, the results suggested that detection of genetic damage using MN assay is sensitive enough at a lower dose in contrast to IAEA manual where the detection limit is only 0.2-0.3 Gy.

Keywords: Antioxidants, Human lymphocytes, Lipid peroxidation, Micronucleus, X-ray

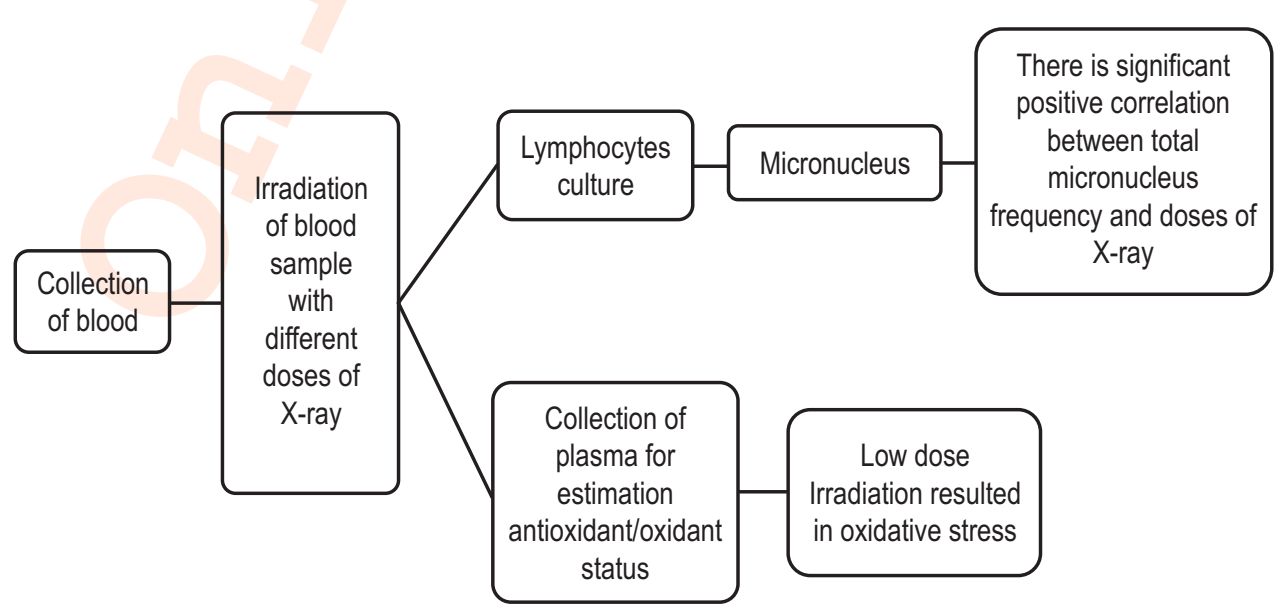

How to cite : Zosangzuali, M., L. Pachuau, K.S. Pau and Zothansiama: Effects of low-dose irradiation on chromosomal damage and oxidative stress in cultured human peripheral blood. J. Environ. Biol., 41, 908-914 (2020). 


\section{Introduction}

lonizing radiation have the ability to directly interact with the cellular components and causes ionization of biomolecules and initiate sequence of events leading to patho-physiological changes (Lehnert, 2007). The increasing use of ionizing radiation in medical diagnosis and treatment has raised concern about its potential long-term effects on human health as prolonged exposure to low-dose radiation has been found to cause adverse health effects including cancer (Gilbert, 2009; Richardson et al., 2015). The use of X-rays has become a popular medical diagnosis and presents a major source of radiation exposure for the general population. Due to their high energy content, $\mathrm{X}$-ray exposure can injure normal cells, alter genetic materials and induce multiple changes in biomolecules (Hall, 2000; Azzam et al., 2012). Although high doses of ionizing radiation are clearly known to produce deleterious consequences such as cardiovascular diseases and cataracts in human (UNSCEAR, 2006; Baselet et al., 2016), the potential risk of low-dose exposure is still a matter of debate (Feinendegen et al., 2011; OECD, 2016). The biological effects of ionizing radiation such as X-rays are mainly related to damages they cause to DNA, by inducing single-strand DNA breaks, double-strand DNA breaks, DNA base alterations and DNA-DNA cross-links (Ward, 1998; Hall, 2009). The potential genotoxicity of ionizing radiation can be determined by micronuclei assay, which is an effective tool to evaluate the genotoxic or clastogenic effects of physical and chemical agents (Fenech et al., 1999). Measurement of micronuclei frequency is extensively used in molecular epidemiology and cytogenetics to evaluate the presence and the extent of chromosomal damage in human population exposed to genotoxic agents (Maffei et al., 2002; Kirsch-Volders et al., 2011; Vellingiri et al., 2014; Zothansiama et al., 2017; Zothansiama et al., 2019).

lonizing radiation directly interacts with atoms or molecules and generates highly reactive oxygen species (ROS) such as hydroxyl radicals $(\mathrm{OH})$ that inflict oxidative damage in cell (Adams, 1986; Le Caër, 2011). Previous studies have reported an increase in the production of endogenous ROS due to exposure to high dose of ionizing radiations (Zhou et al., 2011; Kohanoff and Artacho, 2017). Excessive generation of ROS results in oxidative stress and attacks molecules in the membranes and tissues resulting in various diseases such as cardiovascular diseases, lens opacity of the eyes, lung disease and cancer (Yoshikawa and Naito, 2002; Wang et al., 2016). Although cells are equipped with an impressive repertoire of antioxidants to counterbalance oxidative stress by neutralizing ROS, excess generation of ROS may sometimes overwhelm the endogenous antioxidants and cause oxidative cellular damage (Kono and Fridovich, 1982; Jagetia and Shetty, 2016). Reactive oxygen species, due to their extreme reactivity are not amenable to direct measurement in biological material. Therefore, altered levels of antioxidative enzymes such as glutathione-s-transferase, superoxide dismutase, catalase, glutathione peroxidase, and small-molecule antioxidants such as glutathione are routinely used to assess oxidative stress. Elevated levels of ROS alter lipids by producing lipid peroxides such as malondialdehyde and 4-hydroxynonemal (Burton and Traber, 1990). Lipid peroxidation has been reported to be associated with various pathological conditions and is used as a marker of oxidative stress (Gutteridge, 1995).

According to the United Nations Scientific Committee on Atomic Radiation, low-dose radiation (LDR) include radiation < $200 \mathrm{mGy}$ for low linear energy transfer (LET) radiation or $50 \mathrm{mGy}$ for high LET radiation (Liu et al., 2007, UNSCEAR, 1994). Although several studies have reported increased levels of chromosomal aberrations in human lymphocytes exposed to lowdoses of ionizing radiations (Andreassi et al., 2009; Zakeri and Hirobe, 2010; Sakly et al., 2012), contradictory results have been reported on the genotoxic effects of low-doses of ionizing radiation by various workers (Demirel et al., 1997; Thierens et al., 2002; Joseph et al., 2004). Thus, there is an increasing concern over the magnitude of health risks from exposures to man-made radiation such as diagnostic X-rays that involve low doses (UNSCEAR, 2006). The risk associated with LDR and understanding intracellular responses are of social importance. In views of this, this study was carried out to evaluate in-vitro effects of low-dose radiation on chromosomal damage and antioxidant levels in cultured human peripheral blood.

\section{Materials and Methods}

Collection of blood sample: Blood samples were collected by venipuncture from healthy male and female of 26 years old, nonsmoking volunteers, who did not have any previous history of radiation exposure for diagnostic or treatment purpose, tobacco and alcohol use and intake of medicine for the last one year. Blood samples were collected under sterile conditions in heparinized tubes. The study was approved by the Human Ethics Committee, Mizoram University, Aizawl, India vide approval No. MZU/IHEC/2016/001.

Irradiation of blood: Irradiation of blood was performed in the Department of Radio-diagnosis and Imaging, Civil Hospital, Aizawl, Mizoram. Blood collected from the donors were exposed to a diagnostic X-rays source (Allengers 325 FC, Allengers Medical System Private Ltd., Solan, HP, India) in a polypropylene phantom (dimensions: $30 \times 30 \mathrm{~cm}^{2}$ ), placed transversally to the axis of irradiation source. During irradiation process, radiation field was set at $20 \times 20 \mathrm{~cm}^{2}$, and the distance between the surface of the phantom and the source of radiation was $65 \mathrm{~cm}$. Blood samples were irradiated at $97 \mathrm{kVp}$ with $300 \mathrm{mAs}$. The average dose rate of exposure was measured using RaySafe. An average dose rate of 19.6 mGysec $^{-1}$ was given for 1.3, 2.6, 5.1, 10.2 and $15.3 \mathrm{sec}$ for the total exposure doses of $25,50,100,200$ and 300 $\mathrm{mGy}$, respectively, at an interval of $1 \mathrm{~min}$. All samples were 
irradiated at room temperature. After exposure, the blood samples were allowed to sediment and the buffy coat was collected in a sterile tube and immediately stored at $4{ }^{\circ} \mathrm{C}$ for further use.

Lymphocyte culture and micronucleus assay: Lymphocyte were cultured following the method of Fenech and Morley (1985). Briefly, the blood was allowed to sediment and the buffy coat was collected in individual sterile glass tubes. After counting the viable cells with haemocytometer, $1 \times 10^{6}$ nucleated cells were inoculated into sterile glass tubes containing RPMI-1640 medium supplemented with $10 \%$ fetal calf serum and phytohemagglutinin as mitogen. The cells were allowed to grow for the next $44 \mathrm{hr}$ in a humidified atmosphere of $5 \% \mathrm{CO}_{2}$ at $37{ }^{\circ} \mathrm{C}$. Cytochalasin $\mathrm{B}$ was added at a final concentration of $5 \mathrm{\mu gml}^{-1}$ to block cytokinesis and cells were allowed to grow for another $28 \mathrm{hr}$. Cells were harvested at the end of $72 \mathrm{hr}$ after initiating lymphocyte culture by centrifugation. A mild hypotonic solution was added to the cell pellet so as to retain the cell membrane. Cells were then fixed with freshly prepared Carnoy's fixative (methanol: acetic acid, 3:1). Cell suspension was placed in a pre-cleaned coded slides to avoid observer's bias and spread by air blowing. The cells were stained with acridine orange and scored under a fluorescence microscope (DM 2500, Leica Mikrosysteme Vertrieb $\mathrm{GmbH}$, Wetzlar, Germany). A total of 1000 binucleate cells (BNC) with well-preserved cytoplasm were scored from each individual for the presence of micronuclei (MN) according to the criteria described by Fenech et al. (2003).

Estimation of biochemical parameters: Antioxidants were estimated in the plasma of each individual. Total protein contents were determined by the method of Lowry et al. (1951) using bovine serum albumin as standard.

Glutathione (GSH): GSH content was measured using the method described earlier (Moron et al., 1979). Briefly, $900 \mu \mathrm{l}$ of $0.02 \mathrm{M}$ sodium phosphate buffer ( $\mathrm{pH} 8.0$ ) and $20 \mu \mathrm{l}$ of $10 \mathrm{mM} \mathrm{5,5^{ \prime } -}$ dithio-2-nitroben-zoic acid (DTNB) were mixed with $80 \mu$ of plasma and incubated for $2 \mathrm{~min}$ at room temperature. The absorbance of the sample was read against blank at $412 \mathrm{~nm}$ on a UV-Visible spectrophotometer (SW 3.5.1.0. Biospectrometer, Eppendorf India Ltd., Chennai), and GSH concentration was calculated from the standard curve and expressed in $\mu \mathrm{molmg}^{-1}$ of total protein.

Glutathione-s-transferase (GST): GST activity was estimated by the method of Beutler (1984). Briefly, $850 \mu$ l of phosphate buffer was mixed with $50 \mu \mathrm{l}$ of $20 \mathrm{mM}$ 1-chloro-2, 4-nitrobenzene (CDNB), incubated for $10 \mathrm{~min}$ at $37^{\circ} \mathrm{C}$ followed by the addition of $50 \mu \mathrm{l}$ each of plasma and $20 \mathrm{mM} \mathrm{GSH}$. The blank consisted of all the reagents and distil water was added instead of plasma. The absorbance of blank and test was measured at $360 \mathrm{~nm}$ and enzyme activity was expressed in unit $\mathrm{mg}^{-1}$ of total protein.

Superoxide dismutase (SOD): SOD activity was measured by the method of Fried (1975). Briefly, $100 \mu \mathrm{l}$ each of $186 \mu \mathrm{M}$ phenazine methosulphate and plasma were mixed with $200 \mu$ l of $780 \mu \mathrm{M}$ nicotinamide adenosine dinucleotide (NADH) and $300 \mu \mathrm{l}$ of $3 \mathrm{mM}$ nitrobluetetrazolium. After incubation for $90 \mathrm{sec}$ at $30^{\circ} \mathrm{C}$, $1 \mathrm{ml}$ of acetic acid and $4 \mathrm{ml}$ of $\mathrm{n}$-butanol were added to stop the reaction. The blank consisted of all the reagents, and distil water was added instead of plasma. The absorbance of test and blank was measured at $560 \mathrm{~nm}$ and the enzyme activity was expressed in unit ( $1 \mathrm{U}=50 \%$ inhibition of NBT reduction) $\mathrm{mg}^{-1}$ protein.

Lipid peroxidation: Lipid peroxidation was estimated by the method of Beuege and Aust (1978) and expressed in terms of malondialdehyde (MDA) content. Briefly, plasma was added to a mixture containing $10 \%$ trichloroacetic acid, $0.8 \%$ thiobarbaturic acid and $0.02 \mathrm{~N} \mathrm{HCl}$ in $1: 2$ ratio. The mixture was boiled for $10 \mathrm{~min}$ in a boiling water bath, cooled immediately and centrifuged at $1000 \mathrm{rpm}$ for $10 \mathrm{~min}$. The supernatant was collected and its absorbance was read at $535 \mathrm{~nm}$ against the blank. The blank contained all the reagents and distil water was added instead of plasma. The malondialdehyde (MDA) concentration of the sample was calculated using extinction coefficient of $1.56 \times 10^{-6}$ $\mathrm{M}^{-1} \mathrm{~cm}^{-1}$.

Statistical analyses: The results are expressed as mean \pm SE. One-way ANOVA followed by Tukey's post-hoc test was used for multiple comparisons. SPSS Ver. 20.0 software (SPSS Inc, Chicago, Illinois, USA) and Graph Pad Prism ver. 6.0 were used for statistical analyses. p-value of $<0.05$ was considered statistically significant.

\section{Results and Discussion}

The frequency of micronuclei (MN) in human peripheral blood lymphocytes exposed to low doses of X-ray was significantly higher than control (0 mGy), except at the lowest dose $(25 \mathrm{mGy})$ where no significant $(p>0.05)$ change was

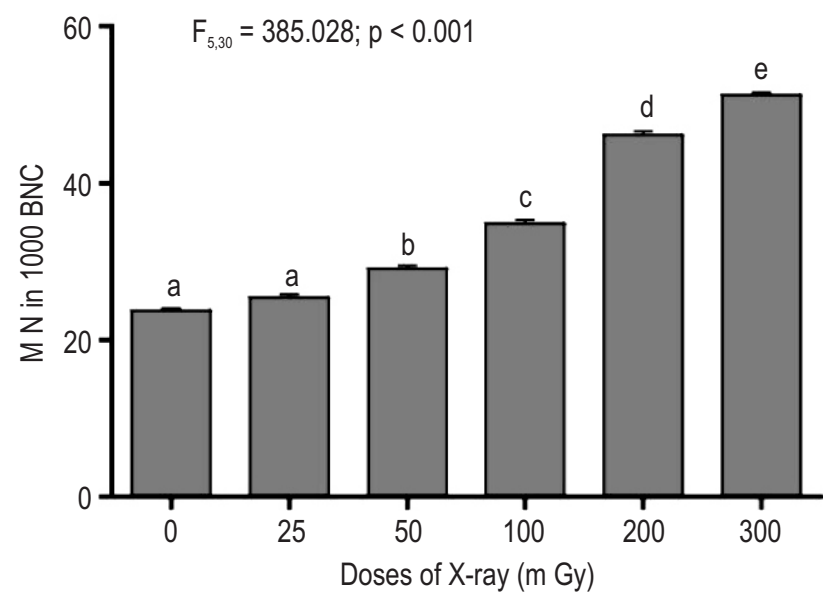

Fig. 1 : Effect of different doses of $X$-rays on the micronuclei formation in the cultured human peripheral blood lymphocyte of healthy donors. Means not sharing same letter are significantly different. 
observed when compared with control (Fig. 1). Significant positive correlation $\left(r^{2}=0.98, p<0.001\right)$ was also observed between total MN frequency and the doses of $\mathrm{X}$-ray exposure in human peripheral blood lymphocytes. Moreover, formation of two micronuclei was observed only in 200 and 300 mGy exposed lymphocytes.

X-ray irradiation at low doses also resulted in dose dependent alleviation of GSH content in human peripheral blood. However, no significant variation was observed between control and lowest dose (25 mGy) in the GSH content (Fig. 2a). In-vitro irradiation of human blood also caused considerable change in GST activities. Increased dose of X-ray significantly reduced the GST activities. Even the lowest dose (25 mGy) of radiation led to significant reduction in the activity of GST when compared with control (Fig. 2b). The activities of SOD did not show significant variation up to $50 \mathrm{mGy}$ exposure. Significant reduction in SOD activity was observed only from the doses $\geq 100 \mathrm{mGy}$. However, no significant change in SOD activity was observed in lymphocytes exposed to doses between $200 \mathrm{mGy}$ and $300 \mathrm{mGy}$ (Fig. 2c). Irradiation induced oxidative stress in human blood was clearly evident by elevated MDA content which is a common indicator of lipid peroxidation (Fig. 3).

The study of the genotoxic effect of ionizing radiation using micronucleus assay has been a major research area and it has been correlated with cytotoxic effect in various studies (Ramalho et al., 1998; Jagetia and Venkatesha, 2006; Ropolo et al., 2012; Koyama et al., 2016). Micronuclei assay is an easy and less cumbersome technique for detecting chromosomal damage in human lymphocytes. Despite extensive use of MN assay as a quantitative indicator of $\mathrm{X}$-rays induced chromosome damage in both in-vitro and in-vivo studies (Ramalho et al., 1988; Maffei et al., 2002; Joseph et al., 2004; Ropolo et al., 2012; Koyama et al., 2016), reports on the effects of fractionated X-rays irradiation on MN formation are limited. Furthermore, the potential effects of very low doses of radiation on the biological system need to be examined as radiation exposure received by human population are of low doses, which are emitted by natural sources such as cosmic rays, radionuclides present in the earth crust and diagnostic X-rays (UNSCEAR, 2006). DNA double strand breaks (DSBs) are the major cytotoxic damage caused by ionizing radiation and are potent inducers of cell death (Morgan et al., 1996). In this study, human peripheral blood lymphocytes exposed to 0 to $300 \mathrm{mGy}$ of $\mathrm{X}$-rays increased the frequency of micronuclei in a linear manner. Cells of human embryo, newborn and children exposed to 0.02 to $2 \mathrm{~Gy}$ irradiation have been reported to induce micronuclei in a dose-dependent manner (Koyama et al., 2016). Similar results have been reported for human lymphocytes exposed to $\mathrm{X}$-rays and $\mathrm{Y}$-rays in earlier studies (Jagetia et al., 2003; Miszczyk et al., 2015). However, linear quadratic response for chromosomal damage after lowdose irradiation has been also reported (Lusiyanti et al., 2016).
Pearce et al. (2012) reported that the risk of developing leukaemia might increase three times among children exposed to CT scans with a cumulative dose of about $50 \mathrm{mGy}$. In contrast, some studies reported insignificant change in the expression of
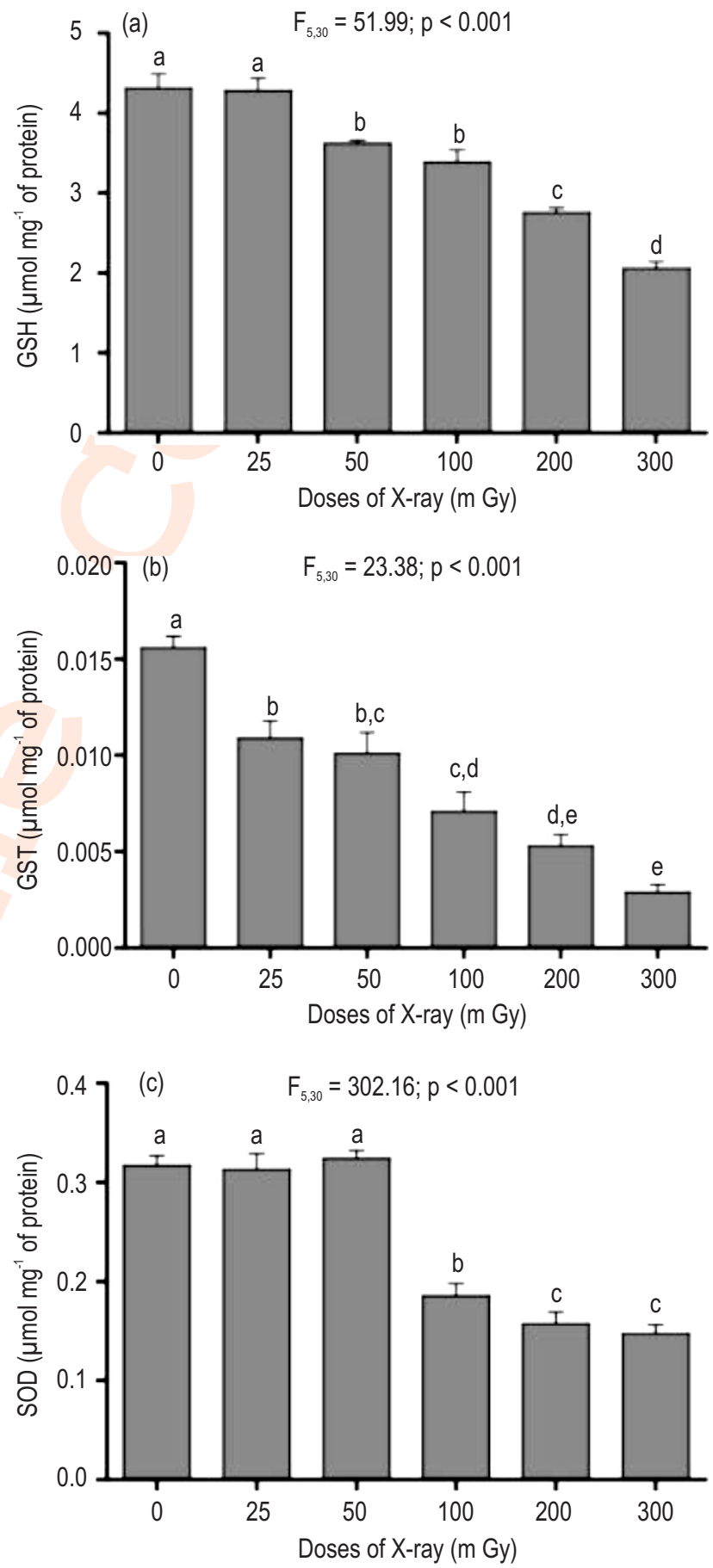

Fig. 2 : Effect of different doses of X-rays on (a) GSH level, (b) GST activity and (c) SOD activity in human peripheral blood lymphocytes of healthy donors. Means not sharing same letter are significantly different. 


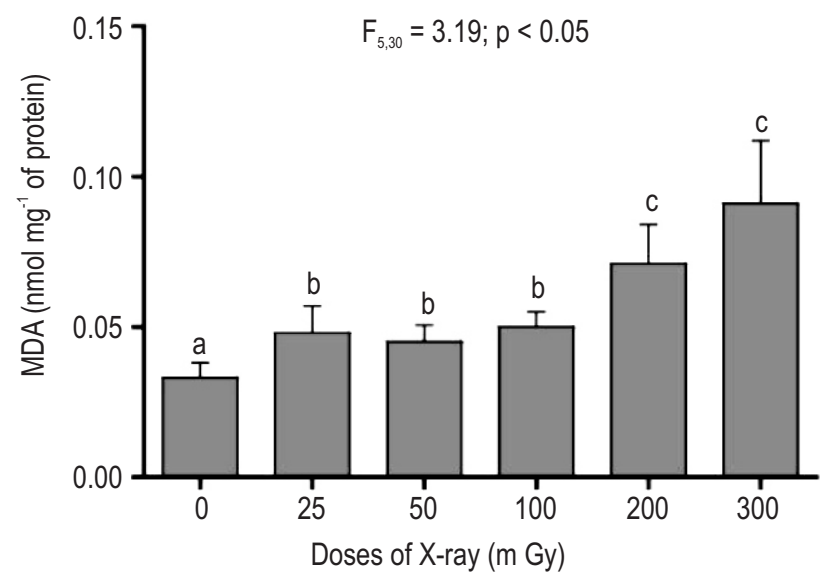

Fig. 3 : Effect of different doses of X-ray on MDA content in human peripheral blood lymphocyte of healthy donors. Means not sharing same letter are significantly different.

radiation responsive genes in irradiated human peripheral white blood cells when compared to data from patients receiving total body irradiation (Amundson et al., 2004, Filiano et al., 2011, Paul et al., 2011). Cervelli et al. (2014) also reported insignificant differences in cell viability or DNA repair in vascular endothelial cells exposed to single or fractionated low-dose irradiation. Previous study also documented that the cultured human lymphocytes can acquire resistance to chromosomal aberrations induced by subsequently high dose radiation when cells are preexposed to low-dose radiation known as adaptive response (Olivieri et al., 1984). Nevertheless, the present study confirms the ability of low doses of X-rays to induce MN formation and the ability of MN assay to estimate DNA damage at a low radiation dose of $50 \mathrm{mGy}$.

The majority of the energy of ionizing radiation such as $X$ rays deposited in cells results in the ejection of electrons from water which subsequently causes the formation of several ROS including the highly reactive hydroxyl radicals $(\mathrm{OH})$ that inflict instant oxidative damage in various biomolecules (Adams, 1986; Le Caër, 2011). lonizing radiations produces these free radicals within micro-seconds, however, their effects persist long after their production due to the cascade of events triggered by these free radicals at molecular and cellular level. This finally leads to an increase in the oxidative stress (OS) and instability of genome in the exposed cells (Einor et al., 2016). lonizing radiation in the presence of molecular oxygen converts hydroxyl, superoxide, and organic radicals into hydrogen peroxide and organic peroxides which are longer lived ROS that continue to damage the cellular genome and other important biomolecules. Moreover, hydrogen peroxide reacts with redox-active metal ions, such as $\mathrm{Fe}^{2+}$ and $\mathrm{Cu}^{2+}$, via Fenton reactions and generates the most deleterious $\mathrm{OH}$ radical and thus intensifying cellular oxidative stress leading to patho-physiology (Biaglow et al., 1992). In this study, human blood lymphocytes exposed to low doses of X-rays showed significantly higher malondialdehyde content indicating increased lipid peroxidation and reduced GSH levels and antioxidant enzyme activities of GST and SOD. Human lymphocytes irradiated with $3 \mathrm{~Gy}$ Y-radiation significantly reduced GST, CAT and SOD activities as compared to control (Bravard et al., 1999). Irradiation of mice resulted in a dose-dependent decline in the GSH concentration and activities of GPx; SOD and CAT with concomitant increase in the lipid peroxidation in various tissues including liver, intestine and skin indicating oxidative cellular damage (Jagetia and Reddy, 2005; Jagetia and Rajanikant, 2015; Jagetia and Shetty, 2016). An increase in lipid peroxidation and reduction in CAT activity was observed in intestinal cells of mice exposed to $2 \mathrm{~Gy}$ of $\mathrm{y}$-rays and $1.6 \mathrm{~Gy}$ of ${ }^{56} \mathrm{Fe}$ radiation (Datta et al., 2012). A number of studies have revealed biochemical changes associated with a prolonged exposure to ionizing radiation and their relationship to the antioxidant system (Achudume et al., 2010; Atasoy et al., 2013). The decrease in the GST and SOD activities in human blood lymphocytes exposed to low doses of $\mathrm{X}$-rays may be due to the persistence of oxidative stress. In addition to rapid burst of ROS observed immediately following irradiation, cells can exhibit prolonged increase in ROS (Yoo et al., 2000), which may lead to oxidative cellular damage such as DNA lesions including double-strand breaks.

Conclusion: Exposure of human blood to low-doses of X-rays has shown to increased MN frequencies and lipid peroxidation, and diminished activities of antioxidant enzymes. This in-vitro experiment reaffirms the ability of low doses of $\mathrm{X}$-rays to trigger micronuclei formation and the ability of micronucleus assay to estimate DNA damage at a radiation dose as low as 50 mGy indicating its sensitivity to detect DNA damage.

\section{Acknowledgment}

We thank the Department of Science and Technology (DST), Government of India, for providing Inspire fellowship to Mary Zosangzuali (DST/INSPIRE Fellowship/[IF170375]).

\section{References}

Achudume, A., B. Onibere, F. Aina and P. Tchokossa: Induction of oxidative stress in male rats subchronically exposed to electromagnetic fields at non-thermal intensities. JEMAA, 2, 482-487 (2010).

Adams, G.E.D.: Radiation carcinogenesis. In: Introduction to the cellular and molecular biology of cancer (Eds.: L.M. Franks and N. Teich). Oxford, Oxford University Press, pp. 154-175 (1986).

Amundson, S.A., M.B. Grace, C.B. McLeland, M.W. Epperly, A. Yeager, Q. Zhan, J.S. Greenberger and A.J. Fornace: Human in-vivo radiation-induced biomarkers: Gene expression changes in radiotherapy patients. CancerRes., 64, 6368-6371 (2004).

Andreassi, M.G., I. Foffa, S. Manfredi, N. Botto, A. Cioppa and E. Picano: Genetic polymorphisms in XRCC1, OGG1, APE1 and XRCC3 DNA repair genes, ionizing radiation exposure and chromosomal DNA damage in interventional cardiologists. Mutat. Res., 666, 5763 (2009). 
Atasoy, H.I., M.Y. Gunal, P. Atasoy, S. Elgun and G. Bugdayci: Immunohistopathologic demonstration of deleterious effects on growing rat testes of radiofrequency waves emitted from conventional Wi-Fi devices. J. Pediatr. Urol., 9, 223-229 (2013).

Azzam, E.I., J.P. Jay-Gerin and D. Pain: Ionizing radiation-induced metabolic oxidative stress and prolonged cell injury. Cancer Lett., $327,48-60$ (2012).

Baselet, B., C. Rombouts, A.M. Benotmane, S. Baatout and A. Aerts: Cardiovascular diseases related to ionizing radiation: The risk of low-dose exposure. Int. J. Mol. Med., 38, 1623-1641 (2016).

Beuege, J.A. and S.D. Aust: Microsomal lipid peroxidation. Methods Enzymol., 30, 302-310 (1978).

Beutler, E.: Red cell metabolism: A manual of biochemical methods. $3^{\text {rd }}$ Edn., New York, Grune and Stratton Inc. (1984).

Biaglow, J.E., J.B. Mitchell and K. Held: The importance of peroxide and superoxide in the X-ray response. Int. J. Radiat. Oncol. Biol. Phys., 22, 665-669 (1992).

Bravard, A., C. Luccioni, E. Moustacchi and O. Rigaud: Contribution of antioxidant enzymes to the adaptive response to ionizing radiation of human lymphoblasts. Int. J. Radiat. Biol., 75, 639-645 (1999).

Burton, G.W. and M.G. Traber: Vitamin E: Antioxidant activity, biokinetics and bioavailability. Annu. Rev. Nutr., 10, 357-82 (1990).

Cervelli, T., D. Panetta, T. Navarra, M.G. Andreassi, G. Basta, A. Galli, P.A. Salvadori, E. Picano and S.D. Turco: Effects of single and fractionated low-dose irradiation on vascular endothelial cells. Atherosclerosis, 235, 510-8 (2014).

Datta, K., S. Suman, B.V.S. Kallakury and A.J. Fornace: Exposure to heavy ion radiation induces persistent oxidative stress in mouse intestine. PLOS ONE, 7, e42224 (2012).

Demirel, S., G. Durakbasi, A.G. Zamani and Aynur: X-ray induced micronucleus frequency assay on radiology technicians' lymphocytes. Turk. J. Med. Res., 15, 56-59 (1997).

Einor, D., A. Bonisoli-Alquati, D. Costantini, T.A. Mousseau and A.P. Møller: lonizing radiation, antioxidant response and oxidative damage: A meta-analysis. Sci. Total Environ., 548, 463-471 (2016).

Feinendegen, L.E., A.L. Brooks and W.F. Morgan: Biological consequences and health risks of low-level exposure to ionizing radiation: Commentary on the workshop. Hlth. Phys., 100, 247-259 (2011).

Fenech, M. and A.A. Morley: Measurement of micronuclei in lymphocytes. Mutat. Res., 147, 29-36(1985).

Fenech, M., N. Holland, W.P. Chang, E. Zeiger and S. Bonassi: The Human micronuclei project-an international collaborative study on the use of the micronuclei technique for measuring DNA damage in humans. Mutat. Res., 428, 271-283 (1999).

Fenech, M., W.P. Chang, M. Kirsch-Volders, N. Holland, S. Bonassi and E. Zeiger: HUMN project: Detailed description of the scoring criteria for the cytokinesis block micronucleus assay using isolated human lymphocyte cultures. Mutat. Res., 53, 65-75 (2003).

Filiano, A.N., H.M. Fathallah-Shaykh, J. Fiveash, J. Gage, A. Cantor, S. Kharbanda and M.R. Johnson: Gene expression analysis in radiotherapy patients and $\mathrm{C} 57 \mathrm{BL} / 6$ mice as a measure of exposure to ionizing radiation. Radiat. Res., 176, 49-61 (2011).

Fried, R.: Enzymatic and non-enzymatic assay of superoxide dismutase. Biochimie., 57, 657-660 (1975).

Gilbert, E.S.: Ionizing Radiation and Cancer Risks: What have we learned from epidemiology? Int. J. Radiat. Biol., 85, 467-482 (2009).
Gutteridge, J.M.C.: Lipid peroxidation and antioxidants as biomarkers of tissue damage. Clin. Chem., 41,1819-1828 (1995).

Hall, E.J.: Radiation biology for pediatric radiologists. Pediatr. Radiol., 39, S57-64 (2009).

Hall, E.J.: Radiation, the two-edged sword: Cancer risks at high and low doses. Cancer J., 6, 343-350 (2000).

Jagetia, G.C. and G.K. Rajanikant: Curcumin stimulates the antioxidant mechanisms in mouse skin exposed to fractionated c-irradiation. Antioxidants (Basel), 4, 25-41 (2015).

Jagetia, G.C. and P.C. Shetty: Augmentation of antioxidant status in the liver of Swiss albino mice treated with jamun Syzygium cumini, Skeels extract before whole body exposure to different doses of cradiation. J. Adv. Res. Biotech., 1, 13 (2016).

Jagetia, G.C. and P. Venkatesha: Treatment of mice with stem bark extract of Aphanamixis polystachya reduces radiation-induced chromosome damage. Int. J. Radiat. Biol., 82, 197-209 (2006).

Jagetia, G.C. and T.K. Reddy: Modulation of radiation induced alteration in the antioxidant status of mice by naringin. Life Sci., 77, 780-794 (2005).

Jagetia, G.C., A. Jayakrishnan, D. Fernandes and M.S. Vidyasagar: Evaluation of micronuclei frequency in the cultured peripheral blood lymphocytes of cancer patients before and after radiation treatment. Mutat. Res., 491, 9-16 (2001).

Jagetia, G.C., P. Venkatesh and M.S. Baliga: Evaluation of the radioprotective effect of Aegle marmelos (L.) Correa in cultured human peripheral blood lymphocytes exposed to different doses of c-radiation: A micronucleus study. Mutagenesis, 18, 387-393 (2003).

Joseph, L.J., U.N. Patwardhan and A.M. Samuel: Frequency of micronuclei in peripheral blood lymphocytes from subjects occupationally exposed to low levels of ionizing radiation. Mutat. Res., 564, 83-88 (2004).

Kirsch-Volders, M., G. Plas, A. Elhajouji, M. Lukamowicz, L. Gonzalez, K.V. Loock and I. Decordier: The in-vitro MN assay in 2011: Origin and fate, biological significance, protocols, high through put methodologies and toxicological relevance. Arch. Toxicol., 85, 873-899 (2011).

Kohanoff, J. and E. Artacho: Water radiolysis by low-energy carbon projectiles from first-principles molecular dynamics. PLOS ONE, 12, 0171820 (2017).

Kono, Y. and I. Fridovich: Superoxide radical inhibits catalase. J. Biol. Chem., 257, 5751-5754 (1982).

Koyama, S., E. Narita, N. Shinohara and J. Miyakoshi: Effect of low-dose $X$-ray irradiation on micronucleus formation in human embryo, newborn and child cells. Int. J. Radiat. Biol., 92, 790-795 (2016).

Le Caer, S.: Water radiolysis: Influence of oxide surfaces on $\mathrm{H}_{2}$ production under ionizing radiation. Water, 3, 235-253 (2011).

Lehnert, S.: Biomolecular action of ionizing radiation (Series in Medical Physics and Biomedical Engineering). Taylor and Francis Group, New York (2007)

Liu, G., P. Gong and L.R. Bernstein: Apoptotic cell death induced by lowdose radiation in male germ cells: Hormesis and adaptation. Crit. Rev. Toxicol., 37, 587-605 (2007).

Lowry, O.H., N.J. Rosebrough, A.L. Farr and R.J. Randall: Protein measurement with the folin phenol reagent. J. Biol. Chem., 193, 265-275 (1951).

Lusiyanti, Y., Z. Alatas, M. Syaifudin and S. Purnami: Establishment of a dose-response curve for $\mathrm{X}$-ray-induced micronuclei in human lymphocytes. Genome Integr., 7, 7-15 (2016). 
Maffei, F., S. Angelini, G.C. Forti, V. Lodi, F.S. Violante, S. Mattioli and P. Hrelia: Micronuclei frequencies in hospital workers occupationally exposed to low levels of ionizing radiation: Influence of smoking status and other factors. Mutagenesis, 17, 405-409 (2002).

Miszczyk, J., K. Rawojć, A. Panek, J. Swakoń, P.G. Prasanna and M. Rydygier: Response of human lymphocytes to proton radiation of $60 \mathrm{MeV}$ compared to $250 \mathrm{kV}$ X-rays by the cytokinesis-block micronucleus assay. Radiother. Oncol., 115, 128-134 (2015).

Morgan, W.F., J.P. Day, M.I. Kaplan, E.M. McGhee and C.L. Limoli: Genomic instability induced by ionizing radiation. Radiat. Res., 146, 247-258 (1996).

Moron, M.S., J.W. Depierre and B. Mannervik: Levels of glutathione, glutathione reductase and glutathione-s-transferase activities in rat lung and liver. Biochim. Biophys. Acta, 582, 67-78 (1979)

Olivieri, G., J. Bodycote and S. Wolff: Adaptive response of human lymphocytes to low concentrations of radioactive thymidine. Science, 223, 594-597 (1984).

Organization for Economic Co-Operation and Development (OECD). Radiological protection science and application. NEA-7265 (2016).

Paul, S. and S.A. Amundson: Gene expression signatures of radiation exposure in peripheral white blood cells of smokers and nonsmokers. Int. J. Radiat. Biol., 87, 791-801 (2011).

Pearce, M.S., J.A. Salotti, M.P. Little, K. McHugh, C. Lee, K.P. Kim, N.L. Howe, C.M. Ronckers, P. Rajaraman, A.W. Sir Craft, L. Parker and A.B. de González: Radiation exposure from CT scans in childhood and subsequent risk of leukaemia and brain tumours: A retrospective cohort study. Lancet, 380, 499-505 (2012).

Ramalho, A., I. Sunjevaric and A.T. Natarajan: Use of the frequencies of micronuclei as quantitative indicators of $\mathrm{X}$-ray-induced chromosomal aberrations in human peripheral blood lymphocytes: Comparison of two methods. Mutat. Res., 207, 141-146 (1988)

Richardson, D.B., E. Cardis, R.D. Daniels, M. Gillies, J.A. O'Hagan, G.B. Hamra, R. Haylock, D. Laurier, K. Leuraud and M. Moissonnier: Risk of cancer from occupational exposure to ionizing radiation: Retrospective cohort study of workers in France, the United Kingdom, and the United States (INWORKS). BMJ, 351, h5359 (2015).

Ropolo, M., C. Balia, P. Roggieri, V. Lodi, M.C. Nucci, F.S. Violante, P. Silingardi, A. Colacci and C. Bolognesi: The micronucleus assay as a biological dosimeter in hospital workers exposed to low doses of ionizing radiation. Mutat. Res., 747, 7-13. (2012).

Sakly, A., J.F. Gaspar, E. Kerkeni, S. Silva, J.P. Teixeira, N. Chaari and H. BenCheikh: Genotoxic damage in hospital workers exposed to ionizing radiation and metabolic gene polymorphisms. J. Toxicol. Environ. Hlth., 75, 934-946 (2012).

Thierens, H., A. Vral, M. Barbe, M. Meijlaers, A. Baeyens and L. De Ridder: Chromosomal radiosensensitivity study of temporary nuclear workers and the support of the adaptive response induced by occupational exposure. Int. J. Radiat. Biol., 78, 1117-1126 (2002).

United Nations Scientific Committee on the Effects of Atomic Radiation. Adaptive responses to radiation in cells and organisms. UNSCEAR report sources and effects of ionizing radiation. New York, NY: United Nations (1994).

United Nations Scientific Committee on the Effects of Atomic Radiation (UNSCEAR). Effects of Ionizing Radiation, Volume I, United Nations, New York (2006).

Vellingiri, B., S. Shanmugam, M.D. Subramanian, B. Balasubramanian, A. Meyyazhagan, K. Alagamuthu, V. Prakash, M. Shafiahammedkhan, S. Kathannan and M. Pappuswamy: Cytogenic endpoints and xenobiotic gene polymorphism in lymphocytes of hospital workers chronically exposed to ionizing radiation in cardiology, radiology and orthopedic laboratories. Ecotoxicol. Environ. Saf., 100, 266-274 (2014).

Wang, F., Q. Sun, J. Wang and N. Yu: Risk of developing cancers due to low-dose radiation exposure among medical $\mathrm{X}$-ray workers in China-results of a prospective study. Int. J. Clin. Exp. Pathol., 9, 11897-11903 (2016).

Ward, J.F.: DNA damage produced by ionizing radiation in mammalian cells: Identities, mechanisms of formation and reparability. Prog. Nucleic Acid Res. Mol. Biol., 35, 95-125 (1998).

Yoo, J.C., H.O. Pae, B.M. Choi, W.I. Kim, J.D. Kim, Y.M. Kim and H.T. Chung: lonizing radiation potentiates the induction of nitric oxide synthase by interferon-gamma (Ifn-gamma) or Ifn-gamma and lipopolysaccharide in bnl cl.2 murine embryonic liver cells: Role of hydrogen peroxide. Free Radic. Biol. Med., 28, 390-396 (2000).

Yoshikawa, T. and Y. Naito: What is oxidative stress? JMAJ, 45, 271-276 (2002).

Zakeri, F. and T. Hirobe: A cytogenetic approach to the effects of low levels of ionizing radiation on occupationally exposed individuals. Eur. J. Radiol., 73, 191-195 (2010).

Zhou, X., N. Li and Y. Wang: Effects of X-irradiation on mitochondrial DNA damage and its supercoiling formation change. Mitochondrion, 11, 886-92 (2011).

Zothansiama, M. Zosangzuali, A. Vanlalruati, G.C. Jagetia, K.S. Pau and N.S. Kumar: Chronic low dose exposure of hospital workers to ionizing radiation leads to increased micronuclei frequency and reduced antioxidants in their peripheral blood lymphocytes. Int. J. Radiat. Biol., 95, 697-709 (2019).

Zothansiama., M. Zosangzuali, M. Lalramdinpuii and G.C. Jagetia: Impact of radiofrequency radiation on DNA damage and antioxidants in peripheral blood lymphocytes of humans residing in the vicinity of mobile phone base stations. Electromagn. Biol. Med., 36, 295-305 (2017) 